\title{
Autologous Pluripotent ALDHbr Stem Cells ALD-451
}

National Cancer Institute

\section{Source}

National Cancer Institute. Autologous Pluripotent ALDHbr Stem Cells ALD-451. NCI

Thesaurus. Code C78466.

A specific population of autologous, pluripotent bone marrow derived cells that express high levels of the cytosolic enzyme aldehyde dehydrogenase (ALDH) with potential protective and neuro-cognition improving activity. Expression of high levels of ALDH is an indicator of the biological activity in heterogenous early stage stem cells. Upon intravenous administration, these ALDH bright cells may protect normal cells and may repair damaged cells. These cells may also protect brain cells from damage and may improve neurocognition. 